\title{
Trial Master File Plan
}

National Cancer Institute

\section{Source}

National Cancer Institute. Trial Master File Plan. NCI Thesaurus. Code C115765.

A proposed method to manage and store trial records during and after a clinical trial. 